\title{
CORRELATION OF HUSBAND'S KNOWLEDGE AND SUPPORT TO IVA TEST BEHAVIOR IN WOMEN OF FERTILE AGE COUPLES IN NAMORAMBE VILLAGE, NAMORAMBE SUB DISTRICT IN 2017
}

\author{
*Hanna Sriyanti Saragih, Julietta Hutabarat \\ *Department of Midwifery of Medan Health Polytechnic of Ministry of Health
}

\begin{abstract}
Abstrak
One of the cervical cancer screening can be done with visual inspection of acetic acid (IVA Test). In Indonesia, almost $70 \%$ of cervical cancers were found in advanced stages (> stage II B). This is due to the low level of screening, which was $<5 \%$ where ideally was $80 \%$. This research is to find out the correlation between husband's knowledge and support to IVA test behavior in women of fertiled age couples. This type of research was analytic descriptive with cross sectional design carried out in Namorambe Village, Namorambe sub district. The population used in the study were all women of fertiled age who live in Namorambe village. Samples were taken by simple random sampling of 58 respondents. Data collection using questionnaires and data analyzed univariate and bivariate using Fisher Exact statistical tests. The results of statistical analysis showed that knowledge's level of the respondents was mostly in less category of 24 people (41.4\%), husband's support for IVA test behavior was at less category of 39 people (67.2\%), the most respondents did not do IVA test of 45 people (77.6 \%). In bivariate analysis, with p-value of 0.001 $<0.05$, it was concluded that there was significant correlation between knowledge with IVA examination behavior, and with a p-value of $0.04<0.05$. It was concluded that there was correlation between husband's support and IVA examination behavior. It was need to increase knowledge about cervical cancer and IVA test through education by health workers through the promotion of reproductive health.
\end{abstract}

Kata kunci IVA Test, Cervical Cancer, Husband Support

\section{A. PENDAHULUAN}

\section{Latar Belakang}

Kanker adalah suatu penyakit yang disebabkan karena adanya pertumbuhan berlebihan atau perkembangan yang tidak terkontrol dari sel-sel jaringa dan sering disertai perubahan perangai sel yang akhirnya mengganggu organ lain. Munculnya sel kanker terjadi sebagai hasil dari mutasi atau perubahan yang tidak normal pada gen yang bertanggung jawab menjaga pertumbuhan sel agar tetap sehat (Andrijino. 2009).

Kanker serviks, yang juga disebut kanker leher rahim adalah kanker yang berasal dari mulut rahim, merupakan kanker terbanyak kedua setelah kanker payudara. Kanker serviks masih banyak ditemukan dinegara berkembang, seperti Indonesia. Di Indonesia, hampir 70\% kanker serviks ditemukan dalam kondisi stadium lanjut (>stadium IIB). Hal ini karena masih rendahnya pelaksanaan skrining, yaitu $<5 \%$, ideal adalah $80 \%$ (Samadi, 2010). Dengan skrining tersebut, maka angka kejadian dan mortalitas diharapkan berkurang (Samadi, 2010).

Deteksi dini kanker serviks yang dikenal umum adalah pap smear, yang biasanya dilakukan di rumah sakit di bagian laboratorium. Namun, ada pula cara alternative yakni metode IVA. IVA merupakan pemeriksaan dengan cara mengamati secara inspekulo serviks yang telah dipulas dengan asam asetat atau asam cuka ( 3-5\% ) selama 1 menit. Daerah yang tidak normal akan berubah warna dengan batas tegas yang menjadi putih (acetowhite), yang mengindikasikan bahwa serviks mungkin memiliki lesi pra kanker. Kanker serviks stadium awal dapat didiagnosa dengan melakukan pemeriksaan citologi melalui IVA. Hampir 50\% penderita kanker serviks ternyata tidak melakukan IVA (Yatim, 2015).

Program pemeriksaan atau screening yang ideal dan optimal untuk kanker serviks menurut WHO sangat dianjurkan pada setiap wanita dan dilakukan setiap 3 tahun pada usia 25 - 50 tahun. Metode ini sudah banyak digunakan di Puskesmas, BPM, ataupun di Rumah Sakit. Metode inspeksi lebih mudah, lebih sederhana, sehingga skrining dapat dilakukan dengan cakupan lebih luas dan diharapkan temuan kanker servik dini akan bisa lebih banyak (Depkes RI. 2009).

Kurangnya tingkat kepercayaan wanita terhadap kesehatan yang meliputi manfaat yang akan diperoleh, kerugian yang didapatkan, hambatan yang akan ditemui bahwa dirinya dapat diserang penyakit serta motivasi diri dan dukungan dari suami atau keluarga yang masih kurang sangat mempengaruhi terhadap sikap wanita dalam pelaksanaan pemeriksaan IVA (Laila Nuranna. 2011).

Wilayah kerja Puskesmas Namorambe terdiri dari 36 desa dimana pada tahun 2016 hanya sekitar 31,76\% (336 orang) wanita dari pasangan usia subur yang telah melakukan pemeriksaan IVA. Berdasarkan data, Tahun 
2016 jumlah wanita usia subur sebanyak 6134 orang dan jumlah wanita pasangan usia subur sebanyak 1058 orang. Desa Namorambe merupakan salah satu desa wilayah kerja Puskesmas Namorambe dengan data jumlah wanita pasangan usia subur sebanyak 368 orang tetapi pada Tahun 2016 tidak ada yang melakukan pemeriksaan IVA.

Berdasarkan data di atas peneliti tertarik untuk meneliti hubungan pengetahuan dan dukungan suami terhadap perilaku pemeriksaan IVA pada wanita pasangan usia subur di Desa Namorambe Kecamatan Namorambe Tahun 2017.

\section{Rumusan Masalah}

Apakah ada hubungan pengetahuan dan dukungan suami terhadap perilaku pemeriksaan IVA pada wanita pasangan usia subur di Desa Namorambe Kecamatan Namorambe Tahun 2017?

\section{Tujuan Penelitian}

1) Menganalisis hubungan pengetahuan terhadap perilaku pemeriksaan IVA pada wanita pasangan usia subur di Desa Namorambe Kecamatan Namorambe

2) Menganalisis hubungan dukungan suami terhadap perilaku pemeriksaan IVA pada wanita pasangan usia subur di Desa Namorambe Kecamatan Namorambe

\section{Manfaat Penelitian}

\section{a. Manfaat Teoritis}

Menambah hasanah ilmu dalam mendukung teori tentang pengetahuan dan dukungan suami yang baik akan meningkatkan perilaku wanita usia subur untuk melakukan pemeriksaan IVA.

b. Manfaat Praktis

1) Dapat memberikan kontribusi bagi profesi dalam meningkatkan mutu pelayanan dan upaya - upaya promotif melalui sosialisasi tentang pemeriksaan IVA kepada masyarakat terutama para pasangan usia subur untuk lebih meningkatkan program yang terkait dengan kesehatan reproduksi.

2) Memberikan motivasi kepada suami untuk memberikan dukungan yang baik kepada istri dalam melakukan pemeriksaan IVA.

\section{B. METODE PENELITIAN}

\section{Jenis dan Desain Penelitian}

Jenis penelitian ini adalah penelitian deskritif analitik dengan desain cross sectional (Notoatmodjo, 2005) yaitu untuk mengetahui hubungan pengetahuan dan dukungan suami terhadap perilaku pemeriksaan IVA pada wanita pasangan usia subur di Desa Namorambe Kecamatan NamorambeTahun 2017.

\section{Lokasi dan Waktu Penelitian}

Penelitian ini dilakukan di Desa Namorambe Kecamatan Namorambe dengan alasan bahwa Desa Namorambe merupakan salah satu wilayah Puskesmas Namorambe dengan jumlah PUS yang melakukan pemeriksaan IVA yang paling rendah dan peneliti bekerja di lokasi penelitian sehingga memudahkan peneliti dalam melakukan penelitian.

Penelitian ini dilakukan pada bulan Desember 2016 Juni 2017 mulai dari penelusuran kepustakaan, pembuatan proposal, pengumpulan data, penulisan laporan penelitian dan sidang hasil penelitian.

\section{Populasi dan Sampel}

Pada penelitian ini, populasi adalah seluruh wanita usia subur yang sudah menikah dan masih memiliki pasangan yang berdomisili di Desa Namorambe Kecamatan Namorambe, dimana berdasarkan pendokumentasian Tahun 2016 berjumlah 138 orang.

Dalam penelitian ini, peneliti menggunakan sampel minimal size (untuk menentukan batas minimal dari besarnya sampel) sampel dapat ditentukan dengan rumus sebagai berikut (slovin) :

$$
\begin{aligned}
\mathrm{n} & =\frac{\mathrm{N}}{1+\mathrm{N}(\mathrm{d})^{2}} \\
\mathrm{n}= & \text { besar sampel } \\
\mathrm{N}= & \text { besar populasi } \\
\mathrm{d}= & \text { tingkat kepercayaan atau ketepatan yang } \\
& \text { diinginkan. }
\end{aligned}
$$

\section{Perhitungan :}

$$
138
$$

n $=$

$$
\begin{aligned}
& \overline{1+138(0,1)^{2}} \\
& n=57,98=58
\end{aligned}
$$

Tehnik pengambilan sampel yang digunakan adalah simple random sampling

\section{Jenis dan Cara Pengumpulan Data}

Data primer dalam penelitian ini diperoleh melalui wawancara dengan mengggunakan kuesioner tentang pengetahuan dan dukungan suami terhadap pemeriksaan IVA yang dibuat oleh peneliti berdasarkan konsep teoritis, sedangkan data sekunder adalah data wanita pasangan usia subur yang diperoleh dari pendokumentasian puskesmas Namorambe.

Instrumen/ Alat pengumpulan data yang digunakan kuesioner pengetahuan dan kuesioner dukungan suami yang didasarkan pada jawaban responden dari semua jawaban yang diberikan dengan menggunakan skala Gutmann yang terdiri dari 2 kategori yaitu "Benar" dan "Salah" dengan ketentuan Benar=1, Salah=0. Jumlah butir soal masing- masing instrumen adalah 20 butir.

\section{Pengolahan dan Analisa Data}

Langkah-langkah pengolahan data pada penelitian adalah dengan proses collecting, proses checking, proses coding, proses entering dan proses processing.

Adapun analisis yang dilakukan adalah analisis univariat disajikan dalam bentuk table distribusi frekuensi dan analisis Bivariat dengan menggunakan rumus alternatif 
chi kuadrat yaitu uji Fisher Exact dengan menggunakan bantuan aplikasi komputer.

\section{HASIL PENELITIAN DAN PEMBAHASAN}

\section{Hasil Penelitian}

a. Deskripsi responden

Berdasarkan hasil penelitian yang dilakukan di Desa Namorambe terhadap 58 responden sebagai sampel penelitian, diperoleh hasil sebagai berikut :

Tabel 1.

Deskripsi Responden

\begin{tabular}{|c|c|c|c|c|}
\hline \multirow{2}{*}{ No } & \multirow{2}{*}{ Variabel } & \multirow{2}{*}{ Kategori } & \multicolumn{2}{|c|}{ Jumlah } \\
\hline & & & $\mathrm{n}$ & $\%$ \\
\hline \multirow[t]{4}{*}{1} & \multirow{4}{*}{$\begin{array}{l}\text { Umur } \\
\text { (tahun) }\end{array}$} & $17-22$ & 12 & 20.7 \\
\hline & & $23-28$ & 23 & 39,7 \\
\hline & & $29-34$ & 16 & 27.6 \\
\hline & & $35-40$ & 7 & 12.1 \\
\hline \multirow[t]{4}{*}{2} & \multirow[t]{4}{*}{ Umur } & SD & 4 & 6.9 \\
\hline & & SMP & 9 & 15.5 \\
\hline & & SMA & 37 & 63.8 \\
\hline & & $\begin{array}{c}\text { PT } \\
\text { (Diploma, } \\
\text { S1) }\end{array}$ & 8 & 13.8 \\
\hline \multirow[t]{2}{*}{3} & \multirow{2}{*}{$\begin{array}{l}\text { Status } \\
\text { Pekerjaan }\end{array}$} & Bekerja & 19 & 32.8 \\
\hline & & $\begin{array}{c}\text { Tidak } \\
\text { Bekerja }\end{array}$ & 39 & 67.2 \\
\hline
\end{tabular}

Berdasarkan tabel 1 diatas diketahui bahwa umur responden pada saat penelitian yang paling muda berumur 17 tahun sedangkan umur responden yang paling tua berumur 40 tahun. Untuk responden terbanyak rata-rata berumur 23-28 tahun yaitu sebanyak 23 orang atau 39,7 $\%$, dan rata-rata umur responden yang paling sedikit berkisar antara 35-40 tahun yaitu sejumlah 7 orang atau $12,1 \%$.

Dari data diatas dapat dilihat ternyata usia responden sebagian besar adalah wanita usia muda.

Berdasarkan tabel 1 diatas dapat diketahui bahwa sebagian besar pendidikan responden adalah SMA sejumlah 37 responden $(63.8 \%), 15.5 \%$ berpendidikan SMP, 13,8\% berpendidikan perguruan tinggi, dan sisanya 4 responden $(6,9 \%)$ berpendidikan SD.

Berdasarkan tabel diatas juga diperoleh hasil sebanyak 19 responden (32.8\%) dengan status pekerjaan adalah bekerja dan sebanyak 39 responden $(67.2 \%)$ tidak bekerja.

\section{b. Analisis Univariat}

Tabel 2

Pengetahuan Responden Tentang Kanker Serviks

\begin{tabular}{lcccc}
\hline \multicolumn{2}{c}{ Serviks } \\
\hline \multirow{2}{*}{ No } & \multirow{2}{*}{ Variabel } & \multirow{2}{*}{ Kategori } & \multicolumn{2}{c}{ Jumlah } \\
\cline { 3 - 5 } & & & $\mathrm{n}$ & $\%$ \\
\hline \multirow{2}{*}{1} & Pengetahuan & Baik & 11 & 18.9 \\
\cline { 3 - 5 } & & sedang & 23 & 39.7 \\
\cline { 3 - 5 } & & Kurang & 24 & 41.4 \\
\hline \multirow{2}{*}{2} & \multirow{2}{*}{ Dukungan Suami } & Baik & 19 & 32.8 \\
\cline { 3 - 5 } & & Kurang & 39 & 67.2 \\
\hline
\end{tabular}

\begin{tabular}{llccc}
\hline \multirow{2}{*}{ No } & \multirow{2}{*}{ Variabel } & \multirow{2}{*}{ Kategori } & \multicolumn{2}{c}{ Jumlah } \\
\cline { 4 - 5 } & & Perilaku & Ya & $\%$ \\
\hline \multirow{2}{*}{$\begin{array}{l}\text { Pemeriksaan } \\
\text { IVA }\end{array}$} & & 13 & 22.4 \\
\cline { 3 - 5 } & & Tidak & 45 & 77.6 \\
\hline
\end{tabular}

Berdasarkan tabel 2 diatas, diketahui bahwa sebanyak 11 responden $(18.9 \%)$ memiliki tingkat pengetahuan baik dan sebanyak 24 responden $(41.4 \%)$ memiliki tingkat pengetahuan Kurang.

Dari table diatas dapat dilihat bahwa 39 orang $(67,2 \%)$ responden kurang memperoleh dukungan suami terhadap perilaku pemeriksaan IVA

Dan dari tabel diatas dapat dilihat bahwa pada umumnya responden tidak melakukan pemeriksaan IVA $(77.6 \%)$.

\section{c. Analisis Bivariat}

Tabel 3

Hubungan Pengetahuan Tentang Kanker Serviks Dengan Perilaku Pemeriksaan IVA di Desa Namorambe Kecamatan Namorambe Tahun 2017

\begin{tabular}{|c|c|c|c|c|c|c|}
\hline \multirow{2}{*}{$\begin{array}{c}\text { Tingkat } \\
\text { Pengetahuan }\end{array}$} & \multicolumn{4}{|c|}{$\begin{array}{c}\text { Perilaku Pemeriksaan } \\
\text { IVA }\end{array}$} & \multirow{2}{*}{ Jumlah } & \multirow{2}{*}{$\begin{array}{c}p \\
\text { Value }\end{array}$} \\
\hline & Ya & $\%$ & Tidak & $\%$ & & \\
\hline Baik & 8 & $72.7 \%$ & 3 & $27.3 \%$ & 11 & \\
\hline Sedang & 2 & $8.7 \%$ & 21 & $91.3 \%$ & 23 & \\
\hline Kurang & 3 & $12.5 \%$ & 21 & $87.5 \%$ & 24 & .0 \\
\hline Jumlah & 13 & $22.4 \%$ & 45 & $77.6 \%$ & 58 & \\
\hline
\end{tabular}

Tabulasi data antara tingkat pengetahuan responden tentang kanker serviks dengan perilaku pemeriksaan IVA menunjukkan adanya penurunan data perilaku pemeriksaan IVA seiring dengan menurunnya pengetahuan responden. Hal tersebut terlihat pada tingkat pengetahuan sedang terdapat $91.3 \%$ responden tidak melakukan pemeriksaan IVA dan pada kategori pengetahuan kurang $87.5 \%$ tidak melakukan pemeriksaan IVA.

Berdasarkan hasil analisis Fisher Exact hubungan antara pengetahuan tentang kanker serviks dengan perilaku pemeriksaan IVA, diperoleh nilai $p$-value sebesar $0,01<0,05$ sehingga kesimpulan yang diperoleh adalah $\mathrm{H}_{0}$ ditolak. Maka, interpretasi dari analisa ini adalah ada hubungan antara pengetahuan tentang kanker serviks dengan perilaku pemeriksaan IVA di Desa Namorambe Kecamatan Namorambe.

Tabel 4

Hubungan Dukungan Suami Dengan Perilaku Pemeriksaan IVA di Desa Namorambe Kecamatan Namorambe Tahun 2017

\begin{tabular}{|c|c|c|c|c|c|c|}
\hline \multirow{2}{*}{$\begin{array}{c}\text { Tingkat } \\
\text { Pengetahuan }\end{array}$} & \multicolumn{4}{|c|}{$\begin{array}{c}\text { Perilaku Pemeriksaan } \\
\text { IVA }\end{array}$} & \multirow[t]{2}{*}{ Jumlah } & \multirow{2}{*}{$\underset{\text { Value }}{p}$} \\
\hline & Ya & $\%$ & Tidak & $\%$ & & \\
\hline Baik & 8 & $72.7 \%$ & 3 & $27.3 \%$ & 11 & \\
\hline Sedang & 2 & $8.7 \%$ & 21 & $91.3 \%$ & 23 & \\
\hline Kurang & 3 & $12.5 \%$ & 21 & $87.5 \%$ & 24 & \\
\hline Jumlah & 13 & $22.4 \%$ & 45 & $77.6 \%$ & 58 & \\
\hline
\end{tabular}


Tabulasi data antara tingkat pengetahuan responden tentang kanker serviks dengan perilaku pemeriksaan IVA menunjukkan adanya penurunan data perilaku pemeriksaan IVA seiring dengan menurunnya pengetahuan responden. Hal tersebut terlihat pada tingkat pengetahuan sedang terdapat $91.3 \%$ responden tidak melakukan pemeriksaan IVA dan pada kategori pengetahuan kurang $87.5 \%$ tidak melakukan pemeriksaan IVA.

Berdasarkan hasil analisis Fisher Exact hubungan antara pengetahuan tentang kanker serviks dengan perilaku pemeriksaan IVA, diperoleh nilai $p$-value sebesar $0,01<0,05$ sehingga kesimpulan yang diperoleh adalah $\mathrm{H}_{0}$ ditolak. Maka, interpretasi dari analisa ini adalah ada hubungan antara pengetahuan tentang kanker serviks dengan perilaku pemeriksaan IVA di Desa Namorambe Kecamatan Namorambe.

\section{Tabel 5}

Hubungan Dukungan Suami Dengan Perilaku Pemeriksaan IVA di Desa Namorambe Kecamatan Namorambe Tahun 2017

\begin{tabular}{|c|c|c|c|c|c|c|}
\hline \multirow{2}{*}{$\begin{array}{c}\text { Dukungan } \\
\text { Suami }\end{array}$} & \multicolumn{4}{|c|}{ Perilaku Pemeriksaan IVA } & \multirow{2}{*}{ Jumlah } & \multirow{2}{*}{$p$ Value } \\
\hline & Ya & $\%$ & Tidak & $\%$ & & \\
\hline Baik & 12 & $63.2 \%$ & 7 & $36.8 \%$ & 19 & \\
\hline Kurang & 1 & $2,6 \%$ & 38 & $97.4 \%$ & 39 & 0.04 \\
\hline Jumlah & 13 & $22.4 \%$ & 45 & $77.6 \%$ & 58 & \\
\hline
\end{tabular}

Tabulasi data pengetahuan tentang kanker serviks dengan perilaku pemeriksaan IVA menunjukkan adanya penurunan perilaku pemeriksaan IVA seiring dengan meningkatnya dukungan suami. Hal tersebut terlihat pada responden yang memperoleh dukungan suami kategori kurang sebanyak 38 orang $(94.7 \%)$ responden tidak melakukan pemeriksaan IVA dan hanya 1 responden saja $(5.3 \%)$ yang melakukan pemeriksaan IVA.

Berdasarkan hasil analisis Fisher Exact hubungan antara pengetahuan responden tentang kanker serviks dengan perilaku pemeriksaan IVA diperoleh nilai $p$-value sebesar 0,04<0,05 dan kesimpulan yang diperoleh adalah $\mathrm{H}_{0}$ ditolak, maka interpretasi dari analisa ini adalah ada hubungan dukungan suami dengan perilaku pemeriksaan IVA di Desa Namorambe Kecamatan Namorambe.

\section{Pembahasan}

a. Hubungan Pengetahuan Tentang Kanker Serviks dengan Perilaku Pemeriksaan IVA.

Hasil analisis Fisher Exact tentang hubungan pengetahuan kanker serviks dengan perilaku pemeriksaan IVA, diperoleh nilai $p$-value sebesar $0,01<0,05$ sehingga dapat disimpulkan $\mathrm{H}_{0}$ ditolak artinya ada hubungan antara pengetahuan tentang kanker serviks dengan perilaku pemeriksaan IVA.

Pengetahuan adalah salah satu faktor pembentuk sikap yang dapat mempengaruhi tindakan seseorang. Notoadmodjo (2012) dalam teorinya mengungkapkan bahwa perilaku yang didasari oleh pengetahuan akan lebih langgeng dari pada perilaku yang tidak didasari pengetahuan. Pengetahuan responden tentang pemeriksaan IVA dapat mempengaruhi perilakunya dalam melakukan pemeriksaan IVA. Semakin baik kategori pengetahuan responden tentang IVA tes, maka akan semakin mempengaruhi perilakunya dalam melakukan pemeriksaan IVA, begitu juga sebaliknya.

Hasil penelitian ini sejalan dengan penelitian yang sebelumnya dilakukan oleh Artiningsih,N (2011) terhadap 115 responden, bahwa dari 58 responden dengan pengetahuan baik, $87,5 \%$ atau 51 orang bersedia untuk melakukan pemeriksaan IVA demikian juga sebaliknya dari 32 responden dengan pengetahuan kurang, 92,7\% atau 30 orang tidak bersedia melakukan pemeriksaan IVA. Responden yang memiliki pengetahuan yang baik mengenai kanker serviks dan pemeriksaan IVA akan cenderung memiliki kesadaran yang besar untuk meningkatkan status kesehatannya sehingga lebih besar kemungkinan untuk melakukan pemeriksaan IVA. Hasil penelitian yang dilakukan Nuranna, L (2008), juga menyimpulkan bahwa pengetahuan merupakan faktor dominan yang berpengaruh dalam prilaku wanita dalam pemeriksaan IVA.

Namun pengetahuan yang baik belum tentu membuat seseorang mau secara sadar melakukan pemeriksaan IVA. Hal ini terbukti dari hasil penelitian dimana dari 11 responden dengan pengetahuan baik masih ditemukan 3 orang $(27.3 \%)$ yang tidak melakukan pemeriksaan IVA. Menurut Kusdu (2015), ada beberapa factor yang mempengaruhi pengetahuan seseorang yaitu tingkat pendidikan, pekerjaan, umur, minat, pengalaman dan informasi. Pengetahuan yang dimiliki seseorang bervariasi hal ini dikarenakan tingkat pemahaman setiap individu berbeda-beda karena pengetahuan seseorang didasari dengan beberapa tingkatan hingga individu tersebut menjadi tahu, memahami, dan mengerti hingga kealam piker (Notoatmodjo, 2012).

Latar belakang pendidikan seseorang juga akan mempengaruhi pengetahuannya. Semakin tinggi pendidikan seseorang maka semakin baik pula pengetahuan yang dimiliki. Hal ini sesuai dengan Arikunto (2010) yang menyatakan bahwa pengetahuan yang dimiliki oleh seseorang dipengaruhi oleh tingkat pendidikan orang tersebut. Jika tingkat pendidikan tinggi maka pengetahuan akan tinggi begitu juga sebaliknya. Tingkat pengetahuan responden yang pada umumnya pada kategori sedang dan kurang, mungkin juga dipengaruhi oleh latar belakang pendidikan responden yang pada umumnya tamatan SMA $(63.8 \%)$ seperti pada table 4.2 diatas.

\section{b. Hubungan Dukungan Suami Terhadap Perilaku Pemeriksaan IVA}

Hasil analisis Fisher Exact tentang hubungan dukungan suami dengan perilaku pemeriksaan IVA, diperoleh nilai $p$-value sebesar $0,04<0,05$, sehingga dapat disimpulkan $\mathrm{H}_{0}$ ditolak artinya ada hubungan antara dukungan suami dengan perilaku pemeriksaan IVA.

Suami sangat berkepentingan terhadap kesehatan reproduksi pasangannya, saling pengertian serta keseimbangan peranan antara kedua suami istri dapat membantu meningkatkan prilaku yang kondusif terhadap peningkatan kesehatan reproduksinya. Pasangan yang selalu berkomunikasi tentang planning keluarga maupun kesehatan reproduksi antara satu dengan yang lainnya akan 
mendapatkan keputusan yang lebih efektif dan lebih baik (BKKBN, 2012).

Hasil penelitian ini sejalan dengan penelitian yang dilakukan oleh Kurniawati Indah (2015), terhadap 61 responden, bahwa dari 35 responden dengan dukungan suami kategori baik, $71.4 \%$ atau 25 orang bersedia untuk melakukan pemeriksaan IVA demikian juga sebaliknya dari 26 responden dengan dukungan suami kategori kurang, 65.4\% atau 17 orang tidak bersedia melakukan pemeriksaan IVA. Dengan $p$ value $0.004<0.005$ berarti terdapat hubungan antara dukungan suami dengan perilaku pemeriksaan IVA dan dengan nilai odd ratio variable dukungan suami sebesar 3,627 berarti bahwa responden dengan dukungan suami yang baik memiliki kemungkinan untuk melakukan pemeriksaan IVA 3,627 kali lebih besar dari pada responden dengan dukungan suami yang kurang. Sheridan dan Radmacher (1992), Sarafino (1998) serta Taylor (1999) dalam Kusdu (2015) membagi dukungan sosial kedalam lima bentuk yaitu dukungan instrumental, dukungan informasional, dukungan emosional, dukungan harga diri dan dukungan pada kelompok.

Dukungan instrumen merupakan penyediaan materi yang dapat memberikan pertolongan langsung seperti pinjaman uang, pemberian barang, makanan serta pelayanan. Bentuk dukungan inii dapat mengurangi stres karena individu dapat langsung memecahkan masalahnya yang berhubungan dengan materi. Dukungan instrumental sangat diperlukan terutama dalam mengatasi masalah. Dukungan informasional melibatkan pemberian informasi, saran atau umpan balik tentang situasi dan kondisi individu. Jenis informasi seperti ini dapat menolong individu untuk mengenali dan mengatasi masalah dengan lebih mudah.Dukungan emosionalmembuat individu memilikiperasaan nyaman, yakin, dipedulikan dan dicintai oleh sumber dukungan sosial sehingga individu dapat menghadapi masalah dengan lebih baik (BKKBN, 2012).

Dukungan ini sangat penting dalam menghadapi keadaan yang dianggap tidak dapat dikontrol.Dukungan pada harga diri dapat berupa penghargaan positif pada individu, pemberian semangat, persetujuan pada pendapat individu dan perbandingan yang positif dengan individu lain. Bentuk dukungan ini membantu individu dalam membangun harga diri dan kompetensi serta bentuk dukungan pada kelompok dapat membuat individu merasa anggota dari suatu kelompok yang memiliki kesamaan minat dan aktivitas sosial dengannya. Dengan begitu individu akan merasa memiliki teman senasib (BKKBN, 2012).

\section{KESIMPULAN DAN SARAN}

\section{Kesimpulan}

a. Mayoritas responden memiliki pengetahuan kategori kurang tentang kanker serviks yaitu sebesar $41.4 \%$

b. Mayoritas responden tidak memperoleh dukungan suami dalam perilaku pemeriksaan IVA $(67.2 \%)$

c. Ada hubungan yang signifikan antara pengetahuan tentang kanker serviks terhadap perilaku pemeriksaan IVA dengan $p$ value 0.001 pada $\alpha 0.05$. d. Ada hubungan yang signifikan antara dukungan suami terhadap perilaku pemeriksaan IVA dengan $\mathrm{p}$ value 0.04 pada $\alpha 0.05$.

\section{Saran}

a. Bagi Responden : Perlu meningkatkan pengetahuannya tentang kanker payudara dengan lebih banyak bertanya kepada petugas kesehatan dan sumber informasi lainnya.

b. Bagi Tempat Penelitian :disarankan bagi tenaga kesehatan setempat untuk memberikan edukasi tentang kanker servik dan pemeriksaan IVA yang lebih intensif lagi melalui promosi kesehatan reproduksi.

c. Bagi Jurusan Kebidanan : hasil penelitian ini dapat dijadikan sebagai masukan untuk tenaga pendidik agar dapat mengembangkan pendidikan kesehatan tentang kesehatan reproduksi

d. Bagi Peneliti selanjutnya : diharapkan penelitian ini dapat bermanfaat sebagai refrensi bagi peneliti selanjutnya dan dapat dikembangkan pada penelitian berikutnya dengan menganalisis berbagai factor penyebab masih rendahnya data wanita usia subur dalam melakukan deteksi dini kanker serviks dengan metode IVA tes.

\section{DAFTAR PUSTAKA}

Andrijino. 2009. Kanker Serviks Edisi kedua. Divisi Onkologi Departemen Obstetri- Ginekologi FK UI. Jakarta.

Arikunto,S.2010. Prosedur penelitian: Suatu pendekatan praktis. Jakarta: Rineka Cipta.

Artiningsih,N.2011. Hubungan tingkat pengetahuan dan sikap wanita usia subur dengan pemeriksaan inspeksi visual asam asetat dalam rangka deteksi dini kanker cervik di Puskesmas Blooto Mojokerto.Tesis, Universitas Sebelas Maret.

Azwar,S. 2008. Sikap Manusia, Teori Dan Pengukurannya. Yogyakarta: Pustaka Pelajar

BKKBN. 2008. Peningkatan partisipasi suami dalam kesehatan reproduksi. Jakarta: BKKBN

Depkes RI. 2009. Pencegahan Kanker Leher Rahim. Alamat URL: http//www.Depkes.go.id. di akses tgl 28 Januari 2017

Kasdu,D. 2015. Faktor Solusi Problem Wanita Dewasa Dalam Kesehatan Reproduksi. Jakarta: Puspa Swara

Kemenkes RI. 2010. Pedoman Teknis Pengendalian Kanker Payudara \& Kanker Leher Rahim. Kementrian Kesehatan RI Direktorat PP\&PL.

Laila Nuranna. 2011 Skrining Kanker Serviks dengan Metode Skrining Alternatif: IVA. Cermin Dunia Kedokteran No. 133 Obstetri dan Ginekologi.

Mubarok. 2007. Promosi Kesehatan Sebuah Pengantar Proses Belajar Mengajar Dalam Pendidikan. Yogjakarta: Graha Ilmu.

Notoatmodjo S. 2010. Pengantar pendidikan dan Perilaku Kesehatan. Jakarta: Rineka Cipta.

2012. Promosi Kesehatan dan Ilmu Perilaku. Jakarta: Rineka Cipta. 
Nuranna, L. 2008. Skrining kanker servik dengan metode IVA, Jurnal Dunia Kedokteran. Alamat URL http:// www.kalbe.co.id di akses tgl 2 Februari 2017

Ocviyanti. 2007. Test Pap, Test HPV dan Servikografi sebagai Pemeriksaan Triase untuk Test IVA positif. Indonesian journal of obstetrics and gynecology No. 4.

Samadi,P. 2010. Yes, I Know Everything About Kanker Serviks! Jakarta: Tiga Kelana.

Salmiah Agus dan Alfian. 2009. Deteksi Dini neoplasia intra epithel serviks dengan metode IVA. Jurnal Kimia Andalas 10 (1).

Sri Dewi Ni Made, dkk. 2012. Hubungan tingkat pengetahuan dan sikap wanita usia subur dengan pemeriksaan inspeksi visual asam asetat (IVA) di Puskesmas Buleleng. Jurnal Kesehatan Magister Kedokteran Keluarga Vol 1, Universitas Sebelas Maret.
Sugiyono. 2013. Metode Penelitian Pendidikan (pendekatan kuantitatif, kualitatif dan R\&D). Bandung: Alfabeta

Sumatris,H. dkk.2013. Hubungan antara perilaku ibu dengan deteksi dini CA.Cervix menggunakan IVA test di Puskesmas Palembang. Jurnal Kesehatan, Politeknik Kemenkes Palembang.

Wayan, N,dkk.2013.Pengetahuan dan Motivasi Wanita Usia Subur tentang Tes Inspeksi Visual Asam Asetat di Propinsi Bali. Jurnal Kesehatan,Departemen Pendidikan Nasional, Universitas Padjadjaran, Fakultas Kedokteran,Program Pascasarjana

Yatim, F. 2015. Penyakit Kandungan. Jakarta:Pustaka Popular Obor 